\title{
O envelhecimento do professor de educação física escolar: repercussões na saúde, prática profissional e cotidiano laboral ${ }^{1}$
}

\section{The aging of physical education school teacher: repercussions in health, professional practice and daily work}

\section{El envejecimiento del profesor de educación física} escolar: repercusiones en la salud, práctica profesional y cotidiano laboral

\author{
iD) Murilo Cabral Gomes \\ Universidade Federal do Rio de Janeiro, Rio de Janeiro, Rio de Janeiro, Brasil \\ murilocg@yahoo.com.br \\ (iD) Alan Camargo Silva \\ Universidade Federal do Rio de Janeiro, Rio de Janeiro, Rio de Janeiro, Brasil \\ alancamargo10@gmail.com \\ iD) Alexandre Moraes de Mello \\ Universidade Federal do Rio de Janeiro, Rio de Janeiro, Rio de Janeiro, Brasil \\ alemoraesrj@yahoo.com.br \\ iD Sílvia Maria Agatti Lüdorf \\ Universidade Federal do Rio de Janeiro, Rio de Janeiro, Rio de Janeiro, Brasil \\ sagatti.rlk@terra.com.br
}

Resumo: Este estudo, de caráter qualitativo, teve como objetivo analisar como o processo de envelhecimento, para professores de Educação

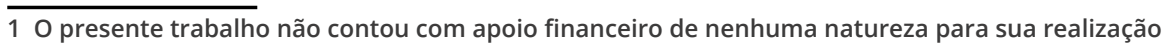


O envelhecimento do professor de educação física escolar: repercussões na saúde... Murilo Cabral Gomes • Alan Camargo Silva • Alexandre Moraes de Mello • Sílvia Maria Agatti Lüdorf

Física escolar, pode repercutir na saúde, na prática profissional e no cotidiano laboral. Foram entrevistados(as) 12 professores(as), formados entre 1970 e 1980 e na faixa etária entre 46 e 66 anos, que atuavam em escolas públicas do Rio de Janeiro há mais de 20 anos. Os dados foram tratados com base na análise de conteúdo. Os resultados indicaram que, embora o ruído ocupacional e o desgaste corporal em geral tenham sido os principais aspectos que impactam na saúde e na prática profissional dos professores na escola, os saberes da experiência cotidiana auxiliam esses docentes a lidarem com o passar dos anos na profissão.

Palavras-chave: Docentes. Escola. Educação Física. Condições de Trabalho.

Abstract: This qualitative study aimed to analyze how the aging process, for Physical Education school teachers, can have repercussions on their health, professional practice and daily work. We interviewed 12 teachers, trained between 1970 and 1980 and between the ages of 46 and 66, who had been working at public municipal schools in Rio de Janeiro for over 20 years. The data were treated based on content analysis. The results indicated that occupational noise and body wear, in general, were the main aspects that impact on the health and professional practice of these school teachers. However, the teachers' routine and working experience help them deal with such an important issue.

Keywords: Teachers. School. Physical education. Working Conditions.

Resumen: Este estudio cualitativo tuvo como objetivo analizar cómo el proceso de envejecimiento, para profesores de Educación Física escolar, puede repercutir en la salud, en la práctica profesional y en el cotidiano laboral. Fueran entrevistados(as) 12 profesores(as), formados entre 1970 y 1980 y en la faja de edad entre 46 y 66 años, que actuaban en escuelas públicas de Rio de Janeiro hace más de 20 años. Los datos fueron tratados en base al análisis de contenido. Los resultados indicaron que aunque el ruido ocupacional y el desgaste corporal hayan sido los principales aspectos que impactaron en la salud y en la práctica profesional de los profesores en la escuela, los saberes de la experiencia 
O envelhecimento do professor de educação física escolar: repercussões na saúde...

Murilo Cabral Gomes • Alan Camargo Silva • Alexandre Moraes de Mello • Sílvia Maria Agatti Lüdorf

cotidiana auxiliaron a esos docentes a lidiar con el pasar de los años en la profesión.

Palabras clave: Docentes. Escuela. Educación Física. Condiciones de Trabajo.

Submetido em: 30/08/2018

Aceito em: 21/10/2019 
O envelhecimento do professor de educação física escolar: repercussões na saúde... Murilo Cabral Gomes · Alan Camargo Silva • Alexandre Moraes de Mello • Sílvia Maria Agatti Lüdorf

\section{Introdução}

O envelhecimento pode ser compreendido como um processo multifacetado que se desenvolve nos planos individual e coletivo, sob diferentes influências biológicas, históricas, sociais e culturais (DEBERT, 2004; GOLDENBERG, 2011). Especialmente sobre o enveIhecimento do professor, deve-se considerar seu marco profissional uma vez que, durante décadas, múltiplas atividades como, por exemplo, planejamentos de aula e outros, elaboração e correção de provas, além das rotinas e conversas com seus pares no cotidiano, constroem a identidade docente (STANO, 2001). Somado a esse ofício laboral, o professor de Educação Física apresenta a particularidade de atuar com as práticas corporais, utilizando-se de seu próprio corpo como um componente de mediação dessas atividades (LÜDORF, 2010).

Essa realidade do professor de Educação Física pode ser compreendida a partir da noção de capital corporal que significa, em termos gerais, o quão os atributos do corpo são julgados em determinado contexto social (SHILLING, 2012). Se, para Goldenberg (2011), o indivíduo se depara com perdas de capital corporal durante o processo de envelhecimento, questiona-se em que medida esse processo pode impactar na vida pessoal e profissional do professor de Educação Física escolar. Para Le Breton (2012), enveIhecer pode ser uma espécie de morte simbólica, especialmente na sociedade ocidental, pois o prestígio social pode declinar com o avançar da idade.

Os professores de Educação Física despendem energia em função de atividades, tais como carregar e montar equipamentos, fazer a segurança dos alunos, demonstrar movimentos, muitas vezes sem aquecimento e de forma repetitiva (BIZET et al., 2010; TRUDEAU et al., 2015). Podem se expor a variações climáticas por nem sempre existirem locais cobertos para realização de aulas e, muitas vezes, possuem elevada carga de trabalho (PALMA, 2014) ou atuam em ambientes ruidosos (LEMOYNE et al., 2007). 
O envelhecimento do professor de educação física escolar: repercussões na saúde... Murilo Cabral Gomes · Alan Camargo Silva • Alexandre Moraes de Mello • Sílvia Maria Agatti Lüdorf

Estudos demonstram que, com o avançar do processo de enveIhecimento, o professor de Educação Física atuante em escolas e/ou em academias de ginástica pode apresentar dificuldades ao desempenhar as suas atividades profissionais, mas também criar outras possibilidades de atuar na profissão (SILVA; LÜDORF, 2010 e 2012; LÜDORF, ORTEGA, 2013; FREITAS et al., 2014). Contudo, ainda são raros os estudos sobre as percepções de professores de Educação Física acerca de eventuais impactos do processo de envelhecimento em sua saúde e prática pedagógica ligada ao ambiente escolar.

Analisar esses aspectos em relação ao professor de Educação Física escolar, sob a ótica daqueles que estão há anos na carreira, potencializa o trato da temática do envelhecimento. A perspectiva sociocultural possibilita que percepções e sensações sejam trazidas à tona, em um instigante olhar da realidade docente, nesse caso, em Educação Física. Este estudo, portanto, tem o objetivo de analisar como o processo de envelhecimento pode repercutir na saúde, na prática profissional e no cotidiano laboral de professores de Educação Física escolar.

\section{Procedimentos metodológicos}

Nesta pesquisa de abordagem qualitativa, foram selecionados(as) 12 professores(as) de Educação Física da rede pública de ensino do Rio de Janeiro, sendo: sete homens e cinco mulheres, com faixa etária de 46 a 66 anos, e graduação obtida de 27 a 40 anos atrás. Os critérios para a seleção dos sujeitos foram: a) Ter 20 anos ou mais como docente na rede pública de ensino, ou seja, estar nas fases de serenidade e de desinvestimento da carreira docente (HUBERMAN, 2007); b) Não estar readaptado ou fora de função, haja vista a importância de conhecer a sua prática pedagógica e o cotidiano laboral. Dessa maneira, esperava-se que as experiências vivenciadas ao longo dos anos pudessem favorecer o aprofundamento das reflexões e/ou riqueza do discurso, o que de fato ocorreu. 
O envelhecimento do professor de educação física escolar: repercussões na saúde...

Murilo Cabral Gomes • Alan Camargo Silva • Alexandre Moraes de Mello • Sílvia Maria Agatti Lüdorf

Para a geração do material empírico, empregou-se a entrevista semiestruturada, que possibilitou uma abordagem mais flexível e aprofundada da história dos entrevistados. Um diário de campo foi utilizado para registros referentes ao desenrolar da pesquisa (MINAYO, 2010). As entrevistas foram realizadas em local de preferência do entrevistado e gravadas em áudio. O número de entrevistas foi estabelecido com o decorrer da investigação considerando-se o princípio da saturação teórica, sendo analisada a recorrência de informações encontradas como elemento delimitador para busca de mais entrevistas (DUARTE, 2002).

Segue o quadro com o perfil dos participantes, referidos aqui por " $\mathrm{H}$ " para homem e " $\mathrm{M}$ " para mulher, acrescidos de um número relativo à ordem em que foram entrevistados.

Quadro 1 - Perfil dos professores de Educação Física entrevistados

\begin{tabular}{|c|c|c|c|c|}
\hline Professor & Idade & $\begin{array}{l}\text { Tempo na rede } \\
\text { pública }\end{array}$ & Ano de formação & $\begin{array}{c}\text { Carga horária em escola } \\
\text { e outras ocupações }\end{array}$ \\
\hline $\mathrm{H} 1$ & 46 & 20 anos & 1989 & $\begin{array}{l}\text { Duas matrículas } \\
16 \mathrm{~h} / 30 \mathrm{~h}\end{array}$ \\
\hline M2 & 47 & 20 anos & 1988 & $\begin{array}{c}\text { Duas matrículas } \\
16 \mathrm{~h} / 16 \mathrm{~h} \\
+16 \mathrm{~h} \text { em colégio particular }\end{array}$ \\
\hline M3 & 53 & 28 anos & 1984 & $\begin{array}{l}\text { Uma matrícula } 16 \mathrm{~h} \\
\text { + Projeto em clube }\end{array}$ \\
\hline $\mathrm{H} 4$ & 52 & 25 anos & 1984 & $\begin{array}{c}\text { Duas matrículas } \\
16 \mathrm{~h} / 16 \mathrm{~h}\end{array}$ \\
\hline H5 & 61 & 29 anos & 1978 & $\begin{array}{c}\text { Duas matrículas } \\
16 \mathrm{~h} / 40 \mathrm{~h}\end{array}$ \\
\hline M6 & 53 & 27 anos & 1982 & $\begin{array}{l}\text { Uma matrícula } 16 \mathrm{~h}+\text { Pro- } \\
\text { fessora de natação }\end{array}$ \\
\hline $\mathrm{H7}$ & 62 & 28 anos & 1980 & $\begin{array}{c}\text { Aposentado + Uma matrícu- } \\
\text { la } 16 \mathrm{~h}\end{array}$ \\
\hline M8 & 66 & 37 anos & 1976 & $\begin{array}{l}\text { Duas matrículas } \\
16 \mathrm{~h} / 30 \mathrm{~h} \\
+ \text { Fisioterapeuta }\end{array}$ \\
\hline M9 & 51 & 29 anos & 1984 & $\begin{array}{c}\text { Aposentada + Uma matrícu- } \\
\text { la } 16 \mathrm{~h}+\text { Arbitragem }\end{array}$ \\
\hline $\mathrm{H} 10$ & 52 & 29 anos & 1984 & $\begin{array}{c}\text { Duas matrículas } \\
16 \mathrm{~h} / 16 \mathrm{~h}\end{array}$ \\
\hline
\end{tabular}


O envelhecimento do professor de educação física escolar: repercussões na saúde... Murilo Cabral Gomes • Alan Camargo Silva • Alexandre Moraes de Mello • Sílvia Maria Agatti Lüdorf

\begin{tabular}{|c|c|c|c|c|}
\hline $\mathrm{H} 11$ & 53 & 26 anos & 1987 & $\begin{array}{c}\text { Duas matrículas } \\
16 \mathrm{~h} / 16 \mathrm{~h}\end{array}$ \\
\hline $\mathrm{H} 12$ & 53 & 29 anos & 1984 & $\begin{array}{c}\text { Duas matrículas } \\
16 \mathrm{~h} / 16 \mathrm{~h}\end{array}$ \\
\hline
\end{tabular}

Fonte: Elaborado pelos autores.

Com base em Turato (2011), os dados foram transcritos e tratados pela análise de conteúdo, seguindo processo que envolve as etapas de leitura flutuante, categorização e subcategorização, conforme critérios de relevância e repetição.

O estudo foi aprovado pelo Comitê de Ética em Pesquisa do Instituto de Estudos em Saúde Coletiva da Universidade Federal do Rio de Janeiro (IESC/UFRJ), com o parecer número: 04/ 2009, processo número: 52/ 2008. Todos os pesquisados concordaram e assinaram o Termo de Consentimento Livre e Esclarecido.

\section{Apresentação e discussão dos resultados}

Essa seção será norteada a partir das três categorias que emergiram dos dados. Ao compreender o impacto do processo de envelhecimento do professor de Educação Física escolar na sua saúde e prática profissional, detectou-se que o "ruído ocupacional" e o "desgaste corporal" foram os principais aspectos ressaltados pelos pesquisados. Já, ao buscar entender o cotidiano laboral, os interlocutores fizeram alusão aos "saberes da experiência" quando se remeteram aos artifícios que aprenderam e construíram em suas atuações pedagógicas durante 20 ou mais anos de magistério.

\section{Ruído ocupacional}

O tempo de carreira na prática docente em Educação Física pode ser considerado um fator de agravo à saúde pelos intensos "barulhos" inerentes ao ambiente escolar ao longo do tempo. Essa 
O envelhecimento do professor de educação física escolar: repercussões na saúde... Murilo Cabral Gomes • Alan Camargo Silva • Alexandre Moraes de Mello • Sílvia Maria Agatti Lüdorf

preocupação aparece nos depoimentos dos professores, o que gerou a categoria chamada de "ruído ocupacional":

A estratégia que eu uso é [...] trabalhar bem a voz pra dar conta de segunda a sexta-feira [...]. A questão do barulho [...] conversei com [...] professores, [...] direção, sugerindo que essa campainha que só aumenta o nível sonoro fosse mudada por uma música clássica que tocasse naquele [...] momento de encerrar [...] um tempo [...]. (H11, 53 anos)

A escola aqui [...] são três recreios, [...] a gente trabalha [...] três tempos dos cinco com muito barulho. [...] A sua voz não vai competir com [...] duzentas crianças ao seu redor, fora a turma que também já faz bastante barulho. Então eu uso apito, mas não [...] o tempo inteiro, o apito é um chamamento, é uma atenção que com o tempo eles vão percebendo. [...] Eu procuro [...] falar [...] com eles reunidos, porque o barulho em volta é muito grande, se eu for tentar [...] projetar minha voz pro outro lado da quadra ou mais distante eu vou perder nesse jogo, porque o barulho é muito grande, não só a turma, mais o recreio. (H12, 53 anos)

Problemas de saúde relacionados à audição e à fonação parecem preocupar os professores de Educação Física escolar. Pelo fato das aulas ocorrerem em espaços abertos, ao mesmo tempo em que o docente deve criar estratégias para ser ouvido pelos alunos, compete com os diversos barulhos que ocorrem no interior da escola, sinal do recreio ou dos intervalos de aula, gritaria das crianças e músicas, ou ainda advindos do exterior da escola, como dos carros e movimentação no entorno, dentre outros. Batista (2008) identificou que esses agravos auditivos acontecem em diferentes espaços da escola.

A análise dos relatos indica que o ruído promove alteração da própria prática pedagógica na escola, levando o docente a criar estratégias para evitar esse incômodo. Assim, a prática pedagógi- 
O envelhecimento do professor de educação física escolar: repercussões na saúde... Murilo Cabral Gomes • Alan Camargo Silva • Alexandre Moraes de Mello • Sílvia Maria Agatti Lüdorf

ca não depende somente das condições didáticas ou técnicas do professor de Educação Física, mas também das condições sonoras que ao longo do tempo impactam negativamente o docente, e como ele as concebe.

O ruído pode ser considerado um agente físico, causador de diversos danos à saúde, sendo reconhecido como a segunda maior causa de perda auditiva no homem (LOPES et al., 2009). Segundo Palma et al. (2009), a exposição ao ruído pode gerar: acidentes de trabalho, estresse agudo, lesões no ouvido interno, dentre outros problemas.

Dentre os professores que relataram incômodo com o ruído, emergiram exemplos de como isso afeta a prática e evidencia-se a preocupação com o aspecto da saúde preventiva, de si ou de outros:

Eu trabalhava muito com apito, [...] descobri que perdi [...] audição, [...] por causa do barulho, [...] pra me prevenir, [...] tentei buscar uma escola que eu trabalhasse numa área coberta, e não usando o apito, não usando muito a voz, e tentando ver se eu consigo de alguma forma controlar ou ser ouvido pelos alunos. (H7, 62 anos)

Alterou sim, [...] a questão [...] da voz, [...] tenho me cuidado mais. Eu busco um pouco mais a atenção dos alunos diminuindo o nível da voz, [...] isso foi uma coisa que ao longo do tempo fez a gente perceber que é necessário esse cuidado. (H11, 53 anos)

Os achados indicam que a experiência docente pode trazer maior preparo para a função face aos níveis de ruído e aos cuidados com a voz. A prática pedagógica do professor de Educação Física pode ser alterada ao longo dos anos em função das possíveis insalubridades ocupacionais que os rodeiam.

Muitos profissionais convivem diariamente com inúmeros tipos do que é conhecido como "poluição sonora". Segundo Lemoyne et al. (2007), no caso da prática docente, os ambientes ruidosos sobrecarregam não somente a audição, mas também a 
O envelhecimento do professor de educação física escolar: repercussões na saúde... Murilo Cabral Gomes • Alan Camargo Silva • Alexandre Moraes de Mello • Sílvia Maria Agatti Lüdorf

fonação com o passar dos anos. Almeida Filho et al. (2012) alertam que o ruído excessivo detectado em escola pode gerar estresse e perda auditiva de acordo com a intensidade e tempo de exposição.

Assim, para além de lesões por movimentos repetitivos, alergias, transtornos emocionais, doenças na pele mediante a exposição solar prolongada e radiação intensa (CANABARRO et al., 2011; OLIVEIRA et al., 2011), o professor de Educação Física parece também estar mais exposto a doenças relacionadas a problemas vocais e auditivos, o que fica mais evidente naqueles atuantes há anos no contexto escolar. Durante o processo de envelhecimento do professor, mais do que alterar a prática pedagógica em si, a própria saúde do docente pode ficar comprometida diante dos problemas advindos do ruído ocupacional.

\section{Desgaste corporal}

Os significados atribuídos ao próprio corpo na prática pedagógica foram objeto de reflexão por parte dos professores de Educação Física. Se por um lado, é compreendido como um elemento-chave para dar aulas e interagir com os alunos, ao longo do tempo na carreira, ressaltaram sentir o desgaste quanto ao aspecto físico, o que foi denominado aqui de desgaste corporal:

Nós professores de Educação Física, nosso corpo [...] ele é, não vou chamar de ferramenta, mas ele é um elemento fundamental pra você exercer a sua profissão. [...] O meu corpo, ele é o meu meio de comunicação com os meus alunos, o meu meio de como lidar com a minha profissão, então ele é realmente o ponto onde eu tenho que me apoiar, eu tento preservar o máximo. (H4, 52 anos)

É que o corpo realmente, não que a gente esteja correndo, pulando [...] a gente não faz nem [...] um milésimo do que eles fazem, mas a gente tem que tá ali realmente com intensidade. [...] Eu tenho [...] 12 turmas com quarenta crianças me olhando 
O envelhecimento do professor de educação física escolar: repercussões na saúde... Murilo Cabral Gomes • Alan Camargo Silva • Alexandre Moraes de Mello • Sílvia Maria Agatti Lüdorf

e que, com certeza, a disposição, a alegria, o bom humor, tem que ser resposta da leitura que eles fazem do meu corpo. [...] Eu penso que realmente envelhecer na nossa profissão é complicado, a gente tem que tá sempre muito disposto, [...] porque $o$ aluno [...] nos exige a todo instante. (M2, 47 anos)

Ao longo da minha vida [...] joguei vôlei, [...] praticamente profissionalmente, [...] me deu duas artroses nos joelhos. Então essa parte tá me dificultando [...] e isso tá até me fazendo pensar em parar daqui a uns tempos, porque [...] a minha parte física não tá acompanhando o ritmo deles, eles são adolescentes, e você tem que ser, algumas horas, dinâmica, não é que você tem que fazer os exercícios, [...] mas acho que você tem que ter o mínimo de mobilidade. (M6, 53 anos)

Peculiaridades da atuação do professor de Educação Física escolar podem ser evidenciadas nos relatos ao mencionarem o desgaste corporal, ora relacionado à atividade laboral, ora à funcionalidade corporal. Para o docente, de modo geral, tal como argumenta Nóvoa (1995), os dizeres e ações são disseminados pelo corpo. No caso do professor de Educação Física, essa percepção é, de certa forma, mais explícita, dada a especificidade de sua prática pedagógica. Na visão dos professores entrevistados, o papel e a participação de seus corpos, ao longo dos anos, são aspectos fundamentais no contexto escolar.

Até aqui, os dados vão ao encontro de Lüdorf (2010) quando aponta que o professor de Educação Física escolar possui a particularidade de lidar com as práticas corporais e, de acordo com a atividade que realiza em sua aula, o seu próprio corpo é parte importante e integradora de sua prática pedagógica. Se essa necessidade do corpo físico para intervir no ambiente escolar é uma realidade, questiona-se em que medida tal mediação pedagógica é influenciada pelo processo de envelhecimento docente.

Até onde foi possível verificar, a importância dada pelos pesquisados ao próprio corpo no curso das aulas de Educação Física 
O envelhecimento do professor de educação física escolar: repercussões na saúde... Murilo Cabral Gomes • Alan Camargo Silva • Alexandre Moraes de Mello • Sílvia Maria Agatti Lüdorf

e o desgaste por ela procovado, também relacionado aos próprios efeitos físico-biológicos do envelhecimento, parecem ser uma realidade para os professores de Educação Física que lecionam há muitos anos:

Hoje um professor mais experiente, mais fundamentado, mais embasado, mas com a vitalidade reduzida em função do desgaste do corpo que ao longo desses anos sofreu por uma série de fatores, dentre eles o fator biológico. Envelheci, não tem jeito. [...] A minha funcionalidade hoje corporal ela é infinitamente reduzida em função da idade e dos problemas que eu acarretei ao longo da vida. (H4, 52 anos)

Você não dá cinco tempos de aula com o mesmo pique com sessenta e um anos quando você dá com vinte cinco, [...] é diferente. Hoje eu não tenho a mesma capacidade de produção científica que eu tinha com vinte e seis [...] anos. Não tenho a mesma capacidade de produção didática, pedagógica, [...] eu tô me aposentando, então sabe você realmente diminui o ritmo, não diminui a motivação. [...] Se eu for demonstrar [...] vai ser uma vez só, não posso toda aula. (H5, 61 anos)

A questão da idade também pesa, e o sobrepeso, [...] que eu tô tentando baixar, diminuir o peso porque isso também colabora, mas assim a questão de muitas aulas seguidas no final dá o cansaço muscular nas pernas, e as dores no joelho. (M6, 53 anos)

Esses depoimentos indicam que o desgaste corporal vinculado ao envelhecimento pode trazer modificações no modo de agir, preparar e desempenhar a prática docente de professores com mais experiência no magistério. Pela natureza da sua disciplina, com o passar dos anos, ao mesmo tempo em que há certo declínio em termos físico-biológicos, o professor de Educação Física parece precisar mais ainda do corpo para trabalhar. Noções como "a idade pesa ou cansa" e "o corpo ou a idade não são mais os mesmos" são emblemáticas no que diz respeito ao desgaste na profissão ou na própria saúde. 
O envelhecimento do professor de educação física escolar: repercussões na saúde... Murilo Cabral Gomes • Alan Camargo Silva • Alexandre Moraes de Mello • Sílvia Maria Agatti Lüdorf

O corpo pode ser considerado um impedimento ou uma intimidação ao sujeito com o decorrer do envelhecimento (Le Breton, 2013). Martinez et al. (2010) argumentam que um dos principais elementos apontados como responsáveis pela modificação da capacidade para o trabalho do profissional em fase de amadurecimento é o seu próprio envelhecimento biológico.

Como consequência ou tentativa de superar o aspecto acima mencionado, emergiram dos dados algumas estratégias para lidar com o cansaço, limitações e dores corporais. Os professores buscam maneiras de adaptar ou alterar o modo de gerir as suas aulas ao longo dos anos:

Eu busco sempre pedir ajuda aos meus alunos [...]. Graças a Deus nesses vinte e nove anos os alunos sempre gostaram de levar saco de bola, bambolê, brigam até pra isso, e aí eu tenho que arrumar estratégia, um leva o outro traz [...]. Se eu tiver muito cansada e puder ficar no mesmo andar onde eu estiver com a turma eu procuro ficar, às vezes quando eu tô melhor eu vou pro terraço da escola. [...] Quando eu tô muito cansada [...] dou aula teórica ou passo um DVD pra eles, [...] utilizo um trabalho [...], um desenho [...], escrever sobre o assunto, a gente faz um debate na sala, falo sobre hábitos saudáveis. [...] são as estratégias que eu utilizo até pra me poupar e não envelhecer tão rápido, não acabar tão rápido. (M9, 51 anos)

[...] O meu corpo envelheceu [...]. E isso acaba impactando o meu ritmo das aulas [...] Se eu for comparar o início [...] da carreira, quando eu participava [...] até jogando com os alunos, participando efetivamente das atividades, dos próprios educativos e hoje, faço isso com muita restrição. [...] O meu corpo [...] está limitado fisicamente [...]. Eu tento hoje fazer com que o meu trabalho exija o menor esforço possível do meu corpo e mais das minhas intervenções, com o diálogo com os alunos, através do contato individual com determinados alunos, isso acho que é a grande mudança que eu venho sentindo nesses anos todos. (H4, 52 anos) 
O envelhecimento do professor de educação física escolar: repercussões na saúde... Murilo Cabral Gomes • Alan Camargo Silva • Alexandre Moraes de Mello • Sílvia Maria Agatti Lüdorf

No ponto de vista dos pesquisados, sugere-se que houve uma queda de rendimento das aulas justamente pelo próprio corpo servir como mediação das práticas corporais durante as atividades desenvolvidas na Educação Física escolar. Por vezes, reduzem o número ou a intensidade das atividades ou se poupam fisicamente realizando alguma aula que, a princípio, não fariam antes. Em outras palavras, a performance como docente nas aulas se modifica de algum modo em função do envelhecimento.

É importante destacar que essa interpretação deve ser problematizada à luz das particularidades da profissão. Isso porque, não raro, conforme mencionado pelos entrevistados, a escolha pela Educação Física estava relacionada ao fato de possuírem vivências relacionadas a esportes:

[...] eu joguei vôlei durante trinta anos, então isso também pesa muito, porque eu jogava vôlei até cansar, [...] eu joguei durante muitos anos com alto impacto, com tênis quando era nova que não era adequado, quer dizer, às vezes não fazia alongamento quando era nova, depois da faculdade que eu comecei [...] a prestar mais atenção nisso. (M9, 51 anos)

[...] jogo tênis há quarenta anos, [...] eu achava que não ia estudar Educação Física, [...] só que aí comecei a dar aula de tênis com dezoito anos pra poder ter já algum dinheirinho, aí eu senti que eu tinha facilidade pra ser professora. [...] sempre foi uma preocupação minha [...] com o tempo passando como é que eu ia conseguir adaptar [...] as minhas funções ao meu trabalho, [...] eu já pensava que eu, quando mais velha, eu não teria a mesma energia. [...] então eu fui procurando [...] aceitar naturalmente essa mudança de fase da minha vida, [...] procurava [...] economizar na voz [...] falar menos com os alunos, chamar menos a atenção, diminuir a quantidade de execuções que eu fazia e o excesso de explicações, procurava fazer a coisa mais sintética dando a ordem pra executar pra que eu pudesse descansar, porque é o que ocorre realmente ao longo dos anos [...] (M3, 53 anos) 
O envelhecimento do professor de educação física escolar: repercussões na saúde... Murilo Cabral Gomes · Alan Camargo Silva • Alexandre Moraes de Mello • Sílvia Maria Agatti Lüdorf

O professor de Educação Física acostumado com a prática corporal no trabalho e, em muitos casos, associada ao treinamento esportivo, apresenta um modo característico de lidar com o próprio corpo. Por estar vivenciando os aspectos físico-biológicos decorrentes do processo de envelhecimento, capacidades do corpo para tornar possíveis ações consideradas simples no cotidiano escolar, muitas vezes parecem ficar comprometidas.

Por um lado, os desgastes físicos pelo uso contínuo de suas articulações e musculaturas por um longo período, ou mesmo associados ao próprio desgaste biológico, podem desencadear sentimentos de limitação e desconforto ao docente. Por outro, a vivência ao longo de anos no magistério pode ser de grande valia para o professor de Educação Física uma vez que lhe permite repensar, reavaliar ou reajustar a aplicação de conteúdos e procedimentos relativos ao público atendido e à sua faixa etária (SILVA, LÜDORF, 2013; SILVA, PALMA, LÜDORF, 2013).

Esses achados sobre o envelhecimento docente em Educação Física dialogam com estudos que discutem (in)diretamente a síndrome do esgotamento profissional ou o processo de burnout em professores de escolas (BOTH et al., 2010; MOREIRA et al., 2010; MOREIRA et al., 2010a; GUZMÁN et al., 2010; BIZET et al., 2010; BRUDINIK, 2011; FARIAS; NASCIMENTO, 2012; PIRES et al., 2012). De certo modo, é possível vislumbrar a relação entre o exercício profissional e o desgaste corporal para aqueles que atuam com a Educação Física escolar.

O presente estudo, contudo, avança na compreensão das particularidades de ser e atuar como professor de Educação Física no âmbito escolar, sob uma perspectiva sociocultural, ao trazer a voz e a experiência de alguns profissionais. Assim, corrobora a necessidade de se compreender cada vez mais o professor na ótica da saúde do trabalhador (CORTEZ et al., 2017). 
O envelhecimento do professor de educação física escolar: repercussões na saúde... Murilo Cabral Gomes · Alan Camargo Silva • Alexandre Moraes de Mello • Sílvia Maria Agatti Lüdorf

\title{
Saberes da experiência
}

Nos depoimentos, observa-se a influência do acúmulo de vivências do ofício docente e a mudança da prática pedagógica do professor, a ponto de gerar a categoria "saberes da experiência":

\begin{abstract}
A [...] diferença que eu vejo é que hoje [...] eu tenho muito mais facilidade [...] de parar uma atividade sem aquilo me deixar “nossa eu não cobrei aquele conteúdo" [...]. Aqui [...] nessa comunidade [...] é muito difícil, se você não [...] tem experiência, bagagem, feeling, você realmente não consegue dar uma boa aula de Educação Física porque os alunos têm uma expectativa e você enquanto professor tem uma expectativa completamente diferente. Eles desconhecem qual é o objetivo da Educação Física, pra eles Educação Física é bola. Então não é "bom dia professora" é "Cadê a bola professora?". Eu estou há quinze anos na mesma escola eu já consigo que não me olhem como uma bola [...]. (M2, 47 anos)
\end{abstract}

Aquela questão de você se poupar [...] em relação a termos psicológicos, o jeito que você dá aula, a economia da sua voz, [...] foi com o tempo porque na faculdade a gente não teve essa matéria, essa orientação muito clara. A experiência no Município que foi dando pra gente [...] estratégias, a experiência te dá mais cancha na hora de começar uma aula, de tocar o rumo da aula, de saber a hora de parar, de ir um pouquinho além. Essa experiência toda de quase trinta anos nos dá [...] essa condição de fazer um trabalho acho que até com uma qualidade melhor, e poupando de uma certa forma a sua voz, o seu corpo. (H12, 53 anos)

Em termos gerais, os saberes da experiência se voltam à ideia de que, considerando a complexidade do contexto profissional, é o professor quem arquiteta o seu próprio fazer no cotidiano escolar. O conhecimento teórico-prático adquirido no curso de graduação 
O envelhecimento do professor de educação física escolar: repercussões na saúde... Murilo Cabral Gomes • Alan Camargo Silva • Alexandre Moraes de Mello • Sílvia Maria Agatti Lüdorf

parece ficar aquém das informações e vivências que tal docente experiencia por alguns anos e que são fundamentais no cotidiano. Muitas vezes, o profissional segue uma linha de trabalho apoiada mais no conhecimento empírico do que nas concepções acadêmicas da sua formação (CLARO JUNIOR, FILGUEIRA, 2009; MADEIRA, LIMA, 2010).

Esses achados indicam que o professor de Educação Física, ao envelhecer e experimentar inúmeras vezes as suas práticas, identifica a necessidade de mudar, corrigir e reconstruir suas aulas dentro do mesmo ambiente em que trabalha. Sanchotene e Molina Neto (2013) identificaram, por exemplo, que os professores preparavam as aulas fundamentadas em seus cotidianos e observações sobre o desempenho. Isso pode ser visto em diversos depoimentos em que as observações da própria aula servem como critério de análise:

Percebo reações que antes não existiam e tento compreender que reações são essas, as reações que eu passo a ter em problemas cotidianos com os alunos, reações que às vezes não eram e passaram a ser, eu tento entender por que eu estou reagindo desta forma e não como [...] antes. Verifico nessas reações quais são as positivas e tento mantê-las, verifico quais são as negativas e tento mudá-las, para não só a saúde física, mas a saúde mental, a minha saúde afetiva também que é muito importante neste contexto, então essas são as tentativas do cotidiano que eu tenho feito. (H1, 46 anos)

Eu [...] bem jovenzinha [...] tava mais preocupada com a parte técnica, chegava lá querendo fazer aquele mundo de estafetas, preparativos, e aquilo não atingia os nossos alunos, em que a expectativa era outra, então aquela aulinha, quadradinha, [...] com o tempo a gente vê que não é aquilo que eles precisam, e que a gente tem que trabalhar em cima do que eles gostam para trazer novidades e deixá-los abertos ao novo [...]. (M2, 47 anos) 
O envelhecimento do professor de educação física escolar: repercussões na saúde... Murilo Cabral Gomes · Alan Camargo Silva • Alexandre Moraes de Mello • Sílvia Maria Agatti Lüdorf

Foi possível observar a importância do professor mais experiente e da reflexão sobre o seu trabalho que, atento, procura alterar a sua prática. Por vezes, os discentes são os principais responsáveis na transformação do professor uma vez que o olhar do educando o estimula a pensar e ajustar o seu plano de aula. Esses achados vão ao encontro da ideia de que envelhecer na profissão docente significa uma forma contínua de desenvolvimento profissional (SÁ, SOUZA, 2015; ALVES, LOPES, 2016).

Madeira e Lima (2010) destacam a importância dos saberes da experiência, na medida em que eles podem funcionar como um "filtro" dos outros saberes. Tardif (2014) afirma que, com o enveIhecimento e amadurecimento na profissão, o professor muitas vezes se utiliza dos conhecimentos adquiridos anteriormente e faz uma revisão e uma reavaliação da sua própria prática profissional diária. Esses aspectos se coadunam com a perspectiva de "professor reflexivo" de Contreras (2002) que se baseia na ideia de que a reflexão docente se estabelece pelo processo coletivo representado no convívio escolar cotidiano.

Logo, os saberes da experiência obtidos ao longo da carreira docente dialogam com os conhecimentos próprios da formação e possibilitam aos professores de Educação Física desenvolver estratégias didáticas durante o processo de envelhecimento. Nessa fase da carreira, quando Huberman (2007) menciona haver um desinvestimento, a pesquisa detectou que é através dessas estratégias que os professores procuram atender de forma adequada o programa estabelecido para a sua disciplina na escola e, ao mesmo tempo, tentam lidar com a diminuição de suas condições físicas. Nesse sentido, os relatos ajudam a entender o cotidiano de trabalho desses docentes, isto é, as lógicas pedagógicas dos professores pesquisados em suas atuações no ambiente escolar.

Assim, ainda que o professor de Educação Física reinvente o seu dia a dia de trabalho a partir dos saberes reconstruídos com a experiência docente, as condições de trabalho podem ser cada vez mais consideradas pelos gestores e comunidade escolar a fim de favorecer a melhoria do ambiente laboral (BOTH, NASCIMENTO, 2009). 
O envelhecimento do professor de educação física escolar: repercussões na saúde... Murilo Cabral Gomes · Alan Camargo Silva • Alexandre Moraes de Mello • Sílvia Maria Agatti Lüdorf

\section{Conclusões}

Os professores pesquisados apontaram mudanças substanciais nas dimensões pessoal e profissional quando compararam o início da carreira com o atual momento docente. Foi possível apreender que o mundo do trabalho desses docentes em diálogo com o campo da Saúde e da Educação demonstra como o passar do tempo pode impactar diretamente na sua vida em geral ou no seu ofício.

O ruído ocupacional e o desgaste corporal revelaram-se aspectos merecedores de preocupação por parte dos docentes. As particularidades das condições e do ambiente de trabalho parecem influenciar a prática profissional e a saúde dos professores de Educação Física escolar com o passar dos anos. Diante das especificidades decorrentes da profissão, os professores alteram suas práticas pedagógicas para a conservação e manutenção na carreira, valorizando informações relativas à sua saúde. Já os saberes constituídos durante a experiência de anos na escola permitem- Ihes subsidiar estratégias para lidar com distintas demandas do cotidiano laboral.

A partir do exposto, urge discutir sobre conteúdos acerca do envelhecimento, em uma perspectiva diferente da biológica, em fóruns e espaços de formação da Educação Física, Educação, Saúde e áreas afins. Conhecer as diferentes facetas da carreira e compreender como o passar dos anos influencia na profissão são tarefas imprescindíveis para se pensar o trabalho docente.

Por fim, destaca-se que, embora aqui tenham sido aprofundadas especificamente as experiências e vivências dos professores de Educação Física escolar face às adversidades do seu ambiente de trabalho, tais achados podem iluminar a prática de outros profissionais que envelhecem no campo da Educação e da Saúde. 
O envelhecimento do professor de educação física escolar: repercussões na saúde...

Murilo Cabral Gomes · Alan Camargo Silva • Alexandre Moraes de Mello • Sílvia Maria Agatti Lüdorf

\section{Referências}

ALMEIDA FILHO, N. de; FILLETTI, F.; GUILLAUMON, H. R.; SERAFINI, F. Intensidade do ruído produzido em sala de aula e análise de emissões acústicas em escolares. Arquivos Internacionais de Otorrinolaringologia, São Paulo, v. 16, n. 1, p. 91-95, fev./mar. 2012.

ALVES, K. da S.; LOPES, A. Professores e o envelhecimento: realidades e especificidades no contexto português. Trabalho \& Educação, Belo Horizonte, v. 25, n. 2, p. 61-77, mai./ago. 2016. BATISTA, P. H. Trabalho \& saúde dos professores de Educação Física nas escolas municipais do Rio de Janeiro. 2008. 79 f. Dissertação (Mestrado em Ciências) - Ciências na área de Saúde Pública, Escola Nacional de Saúde Pública Sergio Arouca, Fundação Oswaldo Cruz, Rio de Janeiro, 2008.

BRUDNIK, M. Professional burnout in female and male Physical Education teachers: a four-phase typological model. Human Movement, Wroclaw, v 12, n. 2, p. 188-195, jun. 2011.

BIZET, I.; LAURENCELLE, L.; LEMOYNE, J.; LAROUCHE, R.; TRUDEAU, F. Career changes among physical educators searching for new goals or escaping a heavy task load? Research Quarterly for Exercise and Sport, Reston, v. 81, n. 2, p. 224-232, june. 2010. BOTH, J.; Nascimento, J. V. Intervenção profissional na Educação Física escolar: considerações sobre o trabalho docente. Movimento, Porto Alegre, v. 15, n. 2, p.169-186, abr./jun. 2009. BOTH, J.; NASCIMENTO, J. V.; SONOO, C. N.; LEMOS, C. A. F.; BORGATTO, A. F. Condições de vida do trabalhador docente: associação entre estilo de vida e qualidade de vida no trabalho de professores de Educação Física. Motricidade, Santa Maria da Feira, v. 6, n. 3, p. 39-51, 2010. 
O envelhecimento do professor de educação física escolar: repercussões na saúde...

Murilo Cabral Gomes • Alan Camargo Silva • Alexandre Moraes de Mello • Sílvia Maria Agatti Lüdorf

Canabarro, L. K.; Neutzling, M. B.; ROmbaldi, A. J. Nível de atividade física no lazer dos professores de Educação Física do ensino básico. Revista Brasileira de Atividade Física e Saúde, Pelotas, v. 16, n. 1, p. 11-17, jan./mar. 2011.

CLARO JUNIOR, R. da S.; FILGUEIRAS, I. P. Dificuldades de gestão de aula de professores de Educação Física em início de carreira na Escola. Revista Mackenzie de Educação Física e Esporte, São Paulo, v. 8, n. 2, p. 9-24, 2009.

CONTRERAS, J. A autonomia de professores. São Paulo, Cortez, 2002

Cortez, P. A.; Souza, M. V. R. de; Amaral, L. O.; Silva, L. C. A. da A. Saúde docente no trabalho: apontamentos a partir da literatura recente. Cadernos Saúde Coletiva, Rio de Janeiro, v. 25, n.1, p. 113-122, 2017.

DEBERT, G. G. A reinvenção da velhice: socialização e processos de reprivatização do envelhecimento. São Paulo, Edusp, 2004. DUARTE, R. Pesquisa qualitativa: reflexões sobre o trabalho de campo. Cadernos de Pesquisa, São Paulo, n. 115, p. 139-154, mar. 2002.

FARIAS, G. O.; NASCIMENTO, J. V. Fatores intervenientes na carreira de professores de Educação Física. Pensar a Prática, Goiânia, v. 15, n. 2, p. 272-505, abr./jun. 2012.

FREITAS, D. C.; Palma, A.; COELHO FILHO, C. de A.; LÜDORF, S. M. A. O envelhecer na visão do profissional de Educação Física atuante em academia de ginástica: corpo e profissão. Movimento, Porto Alegre, v. 20, n. 4, p. 1523, 2014.

Goldenberg, M. Corpo, Envelhecimento e Felicidade. Rio de Janeiro: Editora Civilização Brasileira, 2011.

GUZMÁN, L. R.; CISNEROS, F. J. D.; GUZMÁN, E. R. Trabajo docente y estrés: un reto para los profesores de Educación Física. Revista Brasileira de Docência, Ensino e Pesquisa em Educação Física, Cristalina, v. 2, n. 1, p. 79-90, jul. 2010. 
O envelhecimento do professor de educação física escolar: repercussões na saúde...

Murilo Cabral Gomes • Alan Camargo Silva • Alexandre Moraes de Mello • Sílvia Maria Agatti Lüdorf

HUBERMAN, M. O ciclo de vida profissional dos professores. In: NÓVOA, Antônio (org.). Vida de professores. Porto: Ed. Porto, 2007. p. 31-61.

LE BRETON, D. Adeus ao corpo: antropologia e sociedade. 6. ed. Campinas, Papirus, 2013.

LE BRETON, D. Antropologia do corpo e modernidade. 2. ed. Petrópolis: Vozes, 2012.

LEMOYNE, J.; LAURENCELLE, L.; LIRETTE, M.; TRUDEAU, F.

Occupational healh problems and injuries among Quebec's physical educatiors. Applied Ergonomics, Maryland Heights, n. 38, p. 625-634, 2007.

LOPES, A. C.; NELLI, M. P.; LAURIS, J. R. P.; AMORIM, R. B.; MELO, A. D. P. Condições de saúde auditiva no trabalho: investigação dos efeitos auditivos em trabalhadores expostos ao ruído ocupacional. Arquivos Internacionais de Otorrinolaringologia. São Paulo, v. 13, n. 1, p. 49-54, 2009.

LÜDORF, S. M. A. Formação de professores de Educação Física: retratos de uma instituição. Revista Brasileira de Docência, Ensino e Pesquisa em Educação Física, Cristalina, v. 2, n. 1, p. 126-136, jul. 2010.

LÜDORF, S. M. A.; ORTEGA, F. J. G. Marcas no corpo, cansaço e experiência: nuances do envelhecer como professor de Educação Física. Interface - Comunicação, Saúde, Educação, Botucatu, v. 17, n. 46, p. 973-987, jul./set. 2013.

Madeira, M. Z. de A.; Lima, M. da G. S. B. O significado da prática docente na constituição do saber ensinar das professoras do curso de enfermagem da Universidade Federal do Piauí. Texto \& Contexto Enfermagem, Florianópolis, v. 19, n. 1, p. 70-77, jan./ mar. 2010.

MARTINEZ, M. C.; LATORRE, M. do R. D. de O.; FISCHER, F. M. Capacidade para o trabalho: revisão de literatura. Ciência e Saúde Coletiva, Rio de Janeiro, v. 15, supl.1, p. 1553-1561, jun. 2010. 
O envelhecimento do professor de educação física escolar: repercussões na saúde...

Murilo Cabral Gomes • Alan Camargo Silva • Alexandre Moraes de Mello • Sílvia Maria Agatti Lüdorf

MASCARO, S. de A. O que é velhice. São Paulo, Brasiliense, 2004. MINAYO, M. C. de S. O desafio do conhecimento: pesquisa qualitativa em saúde. 12. ed. São Paulo: Hucitec, 2010.

MOREIRA, H. de R.; NASCIMENTO, J. V.; SONOO, C. N.; BOTH, J. Qualidade de vida no trabalho e perfil do estilo de vida individual de professores de Educação Física ao longo da carreira docente. Motriz, Rio Claro, v. 16, n. 4, p. 900-912, out./dez. 2010.

MOREIRA, H. de R.; NASCIMENTO, J. V.; SONOO, C. N.; BOTH, J. Qualidade de vida do trabalhador docente em Educação Física do estado do Paraná, Brasil. Revista Brasileira de Cineantropometria e Desempenho Humano, Florianópolis, v. 12, n. 6, p.435-442. nov./dez. 2010

NÓVOA, A. (org.). Profissão professor. 2. ed. Porto, Ed. Porto, 1995.

OLIVEIRA, L. M. C. de; GLAUSS, N.; PALMA, A. Hábitos relacionados à exposição solar dos professores de Educação Física que trabalham com atividades aquáticas. Anais Brasileiros de Dermatologia, Rio de Janeiro, v. 86, n. 3, p. 445-450, 2011. PALMA, A.; MATTOS, U. A. de O.; ALMEIDA, M. N. de; OLIVEIRA, G. E. M. C. de. Nível de ruído no ambiente de trabalho do professor de Educação Física em aulas de ciclismo indoor. Revista de Saúde Pública, São Paulo, v. 43, n. 2, p. 345-351, 2009.

PALMA, A. E como segue a saúde dos professores de Educação Física? Corpus et scientia, Rio de Janeiro, v. 10, n. 2, p. 1-15, jul./ dez. 2014.

PIRES, D. A.; MONTEIRO, P. A. P.; ALENCAR, D. R. Síndrome de burnout em professores de Educação Física da região nordeste do Pará. Pensar a Prática, Goiânia, v. 15, n. 4, p. 948-965, out./ dez. 2012.

SÁ, M. A. Á. dos S.; SOUZA, D. M. R. de. Envelhecimento ou desenvolvimento profissional? Apontamentos para uma discussão sobre trajetórias docentes. Trabalho \& Educação, Belo Horizonte, v. 24, n. 2, p. 267-280, mai./ago. 2015. 
O envelhecimento do professor de educação física escolar: repercussões na saúde...

Murilo Cabral Gomes • Alan Camargo Silva • Alexandre Moraes de Mello • Sílvia Maria Agatti Lüdorf

SANCHOTENE, M. U.; MOLINA NETO, V. Rotinas, estratégias e saberes de professores de Educação Física: um estudo de caso etnográfico. Revista Brasileira de Educação Física e Esporte, São Paulo, v. 27, n. 3, p. 447-458, set. 2013.

SHILLING, C. The body and social theory. 3. ed. London: Sage Publications, 2012.

SILVA, A. C.; LÜDORF, S. M. A. Envelhecendo como professor de Educação Física: um olhar sobre o corpo e a profissão. Revista da Educação Física/UEM, Maringá, v. 21, n. 4, p.645-654, 4. trim. 2010.

SILVA, A. C.; LÜDORF, S. M. A. Possíveis relações entre corpo, saúde e o envelhecimento do professor de Educação Física. Movimento, Porto Alegre, v. 18, n. 2, p. 187-204, 2012.

SILVA, A. C.; LÜDORF, S. M. A. Prática profissional em Educação Física: rumo a novas experiências com o passar dos anos. Estudos Interdisciplinares sobre o Envelhecimento, Porto Alegre, v. 18, n. 2, p. 411-427, 2013.

SILVA, A. C.; PALMA, A.; LÜDORF, S. M. A. O envelhecimento do professor de Educação Física e sua prática profissional: significados atribuídos ao corpo e à saúde. Pensar a Prática, Goiânia, v. 16, n. 3, p. 817-833, jul./set. 2013.

STANO, R. de C. M. T. Identidade do professor no envelhecimento. São Paulo, Cortez, 2001.

Tardif, M. Saberes docentes e formação profissional. Petrópolis: Vozes, 2014.

TRUDEAU, F.; LAURENCELLE, L.; Lajoie, C. Energy expenditure at work in physical education teachers. Applied ergonomics, Maryland Heights, v. 46, p. 218-223, 2015.

TURATO, E. R. Tratado da metodologia da pesquisa clínico-qualitativa: construção teórico-epistemológica, discussão comparada e aplicação nas áreas da saúde e humanas. 5. ed. Petrópolis, Vozes, 2011. 
O envelhecimento do professor de educação física escolar: repercussões na saúde...

Murilo Cabral Gomes • Alan Camargo Silva • Alexandre Moraes de Mello • Sílvia Maria Agatti Lüdorf

\section{Notas}

\section{Aprovação de comitê de ética em pesquisa}

Pesquisa aprovada pelo Comitê de Ética da Universidade Federal do Rio de Janeiro. Título: O professor de educação física e o envelhecimento: corpo, saúde e (im)possibilidades profissionais.

\section{Publisher}

Universidade Federal de Goiás. Faculdade de Educação Física e Dança. Publicação no Portal de Periódicos UFG. As ideias expressadas neste artigo são de responsabilidade de seus autores, não representando, necessariamente, a opinião dos editores ou da universidade. 